\title{
Construir paz con desarrollo regional, el reto de los Montes de María hoy*
}

\section{Building peace with regional development, the challenge of the Montes de Maria today}

\begin{abstract}
RESUMEN
La construcción de políticas de paz en este periodo del país, así como toda política pública liderada desde el Estado, debe considerar los matices regionales que permitan que el posconflicto se traduzca en una paz duradera y sostenible. Los hacedores de políticas públicas, además de hacer una lectura del conflicto en perspectiva histórica, deben interpretar las dinámicas sociales que determinan la puja por bienes y servicios locales y la interacción de ciudadanos con las instituciones, circunstancias que establecen los intereses que deben ser considerados para transformar los conflictos sociales y políticos con inclusión y representatividad; por ello el presente trabajo da cuenta de una comprensión de la situación de los Montes de María hoy, inserta en un contexto subregional, relacionado con la tenencia de tierras, desde las siguientes perspectivas: despojo y restitución, formalización de zonas de reserva campesina y seguridad y ejércitos antirrestitución, todo ello enfocado al territorio de Montes de María, específicamente en María la Baja y El Carmen de Bolívar.
\end{abstract}

\section{PALABRAS CLAVE}

Conflicto armado, Políticas públicas, Construcción de paz, Despojo, Restitución de tierras.

\begin{abstract}
The construction of peace policies in this period of the country, as well as any public policy led by the State, must consider the regional nuances that allow post-conflict to translate into lasting and sustainable peace. Public policymakers, in addition to reading the conflict in historical perspective, must interpret the social dynamics that determine the bidding for local goods and services and the interaction of citizens with institutions, circumstances that establish the interests that must be considered for transforming social and political conflicts with inclusion and representativeness; the present work shows an understanding of the situation of the Montes de Maria today, inserted in a sub-regional context, related to land tenure, from the following perspectives: dispossession and restitution, formalization of peasant reserve areas and security and anti-restitution armies, all focused on the Montes de Maria territory, specifically in Maria la Baja and El Carmen de Bolivar.
\end{abstract}

\section{KEYWORDS}

Armed conflict, Public policies, Peacebuilding, Dispossession, Land restitution.

* Informe de investigación en el marco del convenio CIDER de la Universidad de los Andes, como insumo para el documento "Políticas de paz y reconciliación: 20 años de experiencias regionales", propuesta de Lineamientos de Política pública de desarrollo regional, paz y reconciliación. en el marco del contrato $N^{\circ}$ DCI/ALA/2012/309-376 Universidad de los Andes, DPS y Unión Europea. 2014.

RAFAELA SAYAS CONTRERAS

Abogada. Docente investigadora de la Universidad de Cartagena. Magíster en Derecho de la Universidad Nacional de Colombia. Ph.D. en Sociología de la Universidad de Belgrano (Argentina). Consultora en Derechos Humanos. Directora del Grupo de Investigación Conflicto y Sociedad. rafaelaester@gmail.com 


\section{INTRODUCCIÓN}

El presente trabajo implicó una investigación de carácter regional; una comprensión de la situación de los Montes de María hoy, pero inserta en un contexto subregional y regional de rezago histórico, como la costa Caribe colombiana, situación que se refleja tanto en los bajos indicadores de desarrollo sociodemográfico como en las preocupantes cifras presentadas en Objetivos de Desarrollo de Milenio de Naciones Unidas.

Así las cosas, es importante avanzar en la diferenciación entre políticas de paz y políticas de transición. Aunque estas últimas puedan ser tenidas en cuenta dentro del marco general de las políticas de construcción de paz, conceptualmente no coinciden con ellas en los objetivos que persiguen. Mientras las políticas de transición se fundamentan en el ideal de corrección fundado en el daño, las políticas de paz buscan transformar el conflicto en un marco de paz estructural. Dos enfoques que implican un reto para el Estado colombiano en la medida que en algunas zonas de la geografía nacional, como en los Montes de María, es manifiesta la debilidad de la institucionalidad y la presencia de una red de clientes, que alimentan las instituciones informales que han venido formalmente constituidas, como lo plantea O'Donnell, circunstancias reflejadas en la escasa cobertura de los Derechos Económicos, Sociales y Culturales-DESC, paquete básico para todos los ciudadanos sin excepción.
En este sentido cabe recordar a Rawls, quien plantea que todas las instituciones democráticas deben tributar al ideal de justicia como mparcialidad en el entendido de concebir a la "sociedad como un sistema justo de cooperación a través del tiempo y del cambio de una generación a otra. Esta idea organizadora central se desarrolla junto con dos idea fundamentales afines: una es la idea de los ciudadanos (aquellos comprometidos en la cooperación) considerados como personas libres e iguales; la otra idea es la de una sociedad bien ordenada, considerada como sociedad efectivamente regulada por una concepción política de justicia" (Rawls, 1995, p.39)

La preocupación que expresan las organizaciones campesinas y las mesas de víctima hoy, y que, a la postre, reflejan el sentir de hombre y la mujer montemariana tiene que ver con: I; El desarrollo rural y la zona de reserva campesina II; La restitución de tierras abandonadas y despojadas III; La seguridad frente a los ejércitos antirrestitución y bandas criminales emergentes. Aspectos que serán tratados a continuación.

\section{Trayectoria del conflicto armado en la re-} gión

Con el propósito de efectuar una aproximación a la reconfiguración histórica del conflicto en esta zona, se recopiló y analizó información de fuentes primarias y secundarias. La información primaria fue suministrada por actores sociales mediante entrevistas semiestructuradas a campesinos, líderes y lide- resas de la zona, la cual se analizó en conjunto con la información secundaria recopilada de notas de prensa del periódico local El Universal de Cartagena y de documentos especializados sobre trabajos de campo de varias instituciones y centros de investigación.

Metodológicamente, se efectuó primero una caracterización de la zona, para luego pasar a una cronología del conflicto armado, tomando como referente los lineamientos estipulados por el Cider en los términos de referencia para el producto de monografías regionales, parámetros para el análisis de la información acerca del conflicto armado regional y para determinar si expresa o no las mismas características de "permanencia y continuidad" manifiestas en el resto del territorio nacional.

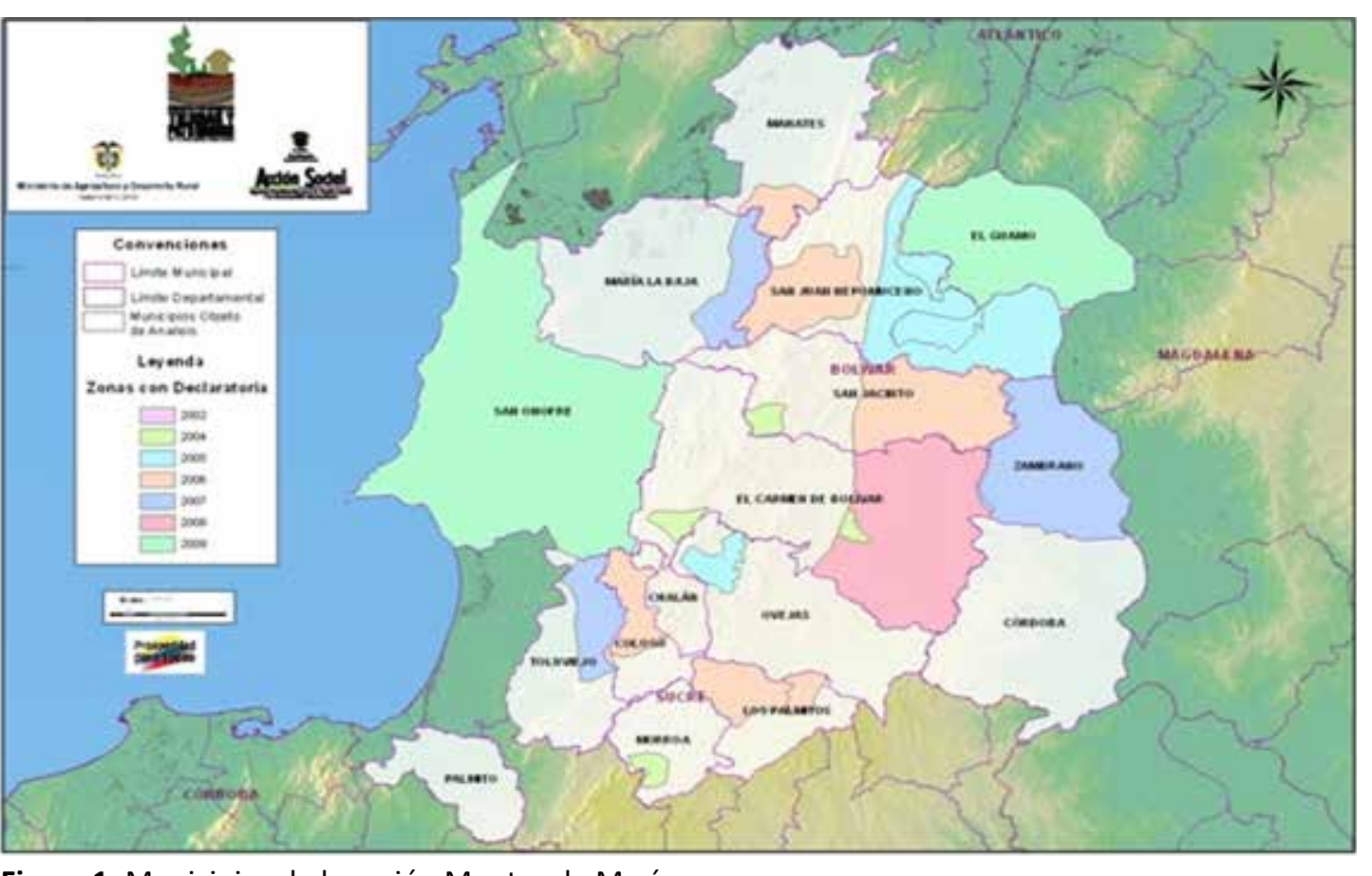

Figura 1. Municipios de la región Montes de María

fuente: Ministerio de Agricultura, 2012

\section{Caracterización de los Montes de María}

Integran la región de los Montes de Maria, los municipios de El Carmen de Bolivar, San Jacinto, San Juan Nepomuceno, María la Baja, El Guamo, Zambrano, Córdoba (departamento de Bolívar) y los municipios de Ovejas, Los Palmitos, San Antonio de Palmito, Morroa, Toluviejo, Colosó, Chalán y San Onofre (Sucre); para un total de 15 municipios.

Los habitantes de los municipios de los Montes de María han venido padeciendo una exclusión social en todos los sentidos, ubicándose como los más pobres entre los pobres, a pesar de que la cooperación internacional y la empresa privada han contribuido a aminorar los efectos de la guerra. Esta región, en el contexto

REVISTA VIS IURIS I No. 3, Vol. 2 I 127 - 158 I Enero-Junio, 2015 I Universidad Sergio A Aboledal IEscuela de Derechoo I Seccional Santa Marta, Sede Centro 
más ha sufrido los embates de la violencia, yectos forestales de palma de aceite y de gasituación que agrava las condiciones de la nadería doble propósito, son asociados con población, si se considera el rezago histórico el abandono y la compra masiva de tierras; de la costa Caribe colombiana con respecto a y también con procesos de especulación otras regiones del país. De hecho, la zona ha tanto muchos de los nuevos propietarios essido teatro de guerra de los actores violentos tán adquiriendo tierras para el desarrollo de en la lucha por el territorio, ante lo cual es corto y mediano plazo, con la expectativa de comprensible la naturaleza crítica de los in- vender posteriormente para la explotación dicadores de desarrollo, frente a la realidad petrolera o de gas (Grupo de Memoria Hisque históricamente ha lanzado a sus pobla- tórica, 2010).

dores a ser campesinos sin tierra, migrantes forzados.

Los habitantes de los Montes de María son campesinos, la mayoría aparceros y poseedores de minifundios, cuyo sustento lo derivaban de labores agrícolas y ganaderas*. EI conflicto introduce alteraciones importantes que determinan una variación de la autosostenibilidad de la familia campesina; por ello es prioritario el estímulo para retomar las labores del campo que constituye la actividad natural de esta población por antonomasia. El cambio sucede cuando son forzados a abandonar sus tierras y despojados de las mismas, dinámica de acumulación de tierras impulsada por diversas actividades económicas que terminan sustituyendo la economía campesina por un modelo económico extractivo. En los departamentos de Sucre y Bolívar, concretamente en los Montes de María, la exploración energética de gas y petróleo, la exploración de aguas subterráneas para el montaje de distritos de riego y el suministro de agua potable a los acueductos regionales y el montaje de ambiciosos pro-

paralizado por el momento, pero que de continuar creciendo los precios nacionales uramente estimulará a sus propietarios darle continuidad (Documento informe de ANUC Montemarianas, s.f.
El abandono y despojo de tierras es generalizado en los campos de todo el territorio nacional; sin embargo, han existido zonas en las que la densidad del despojo ha sido mayor por el escalamiento del conflicto y la disputa del territorio por la riqueza de recursos naturales de la región. En este sentido, una de las zonas de mayor conflictividad y despojo la constituye los Montes de María (Grupo de Memoria Histórica, 2010, p.165), con una de las mayores cifras de expulsión, epicentro de operaciones de una variedad de actores armados (como se explicará en adelante) de violaciones al Derecho Internacional de los Derechos Humanos y del Derecho Internacional Humanitario y de redes de corrupción que han permeado las instituciones y reblandecido la gobernabilidad.

2. Conflictos agrarios previos en la zona: a coordinadora de organizaciones campesinas y las ANUC vs la institucionalidad departamental

La existencia de conflictos sociales en la zona s un buen punto de partida para determinar el entrecruce del conflicto armado con el conflicto social, analizado en un marco de violencia estructural en el sentido planteado por Galtung (1969), quien expresa este tipo de violencia (la estructural), es independiene de la violencia directa (personal), pero que en conjunto, es caldo de cultivo de otros tipos de violencias, puesto que reflejan la injusticia social como exclusión y desigualdad incubada en una sociedad.

Una vez se examina la existencia previa de conflictos en la zona, se procede a presentar una cronología del conflicto, basada en las notas de prensa del diario El Universal*, cronología que se ha dividido en tres etapas: a. 1985 a 1990 (final del periodo presidencial de Virgilio Barco), b. 1991 a 2002 (final del periodo presidencial de Andrés Pastrana), y c. 2001 hasta la fecha (cobija los dos periodos presidenciales de Álvaro Uribe Vélez).

Los conflictos sociales previos en los Montes de María vienen de la mano con los asociados al acceso a la propiedad de la tierra por parte de élites empoderadas en los municipios, frente al campesino analfabeta, pequeño propietario y/o colono. El equilibrio social a principios del siglo XX descansaba, en los Montes de María (al igual que en la costa Caribe), en la reproducción de una sociedad fundada en la dominación que proveía la fuerza de trabajo de las labores del campo, pero que veía lejana el acceso a la propia propiedad. De hecho, Fals Borda registra en su Historia Doble de la Costa, la expoliación de la pequeña propiedad, acaecida en la epoca de la violencia, por las élites terratenientes, gamonales de sus respectivos municipios, historia que de una u otra forma se ha venido repitiendo por otros actores sociales y políticos, pero siempre frente al campesinado indefenso:

"[...] porque la violencia fue un arma de la reacción empleada por grupos y personas 
de las clases capitalistas y terratenientes lista y la negativa respuesta a la canalización regionales que querían aprovechar el caos de las demandas sociales de la población. y el terror para apropiarse de las tierras[...]

sin las dificultades y cortapisas sociales y Por ello, cobra especial relevancia la Asolegales que venían experimentando al ciación Nacional de Usuarios Campesino tratar de expandir sus propiedades, sea (ANUC), y el papel que desempeñó tanto en con escrituras ficticias o mediante la dura la tradición organizativa agraria en la zona de aplicación de la "ley de los tres pasos" los Montes de María como en la toma cam que llevaba a consolidar las fincas peque- pesina de tierras. Uno de los episodios más ña desmontadas para convertirlas en ha- connotados fue el secuestro, tortura y muerciendas ganaderas. La violencia fue, pues, te del líder izquierdista Guillermo Quiroz, empleada como acelerador del proceso líder campesino de las ANUC (EI Universal, de acumulación capitalista en el agro cos- 1985, 16 de dic.), aspecto que retomamos teño, hasta en los confines de la frontera más adelante.

agrícola" (Fals Borda, 2002, p.164).

La ANUC tuvo un papel protagónico en CórQuiere decir ello que los conflictos sociales doba, Bolívar y Sucre, liderando la reivindien los Montes de María son el reflejo de la cación del campesinado sin tierra, llevando lucha por el capital, bien sea del terratenien- a cabo 194 "tomas o recuperaciones" de la te contra el campesino, del colono contra el tierra entre 1971 y 1975; en los municipios hacendado en pos de la consolidación capita- de San Onofre, Tolú, Ovejas, Colosó, princi-

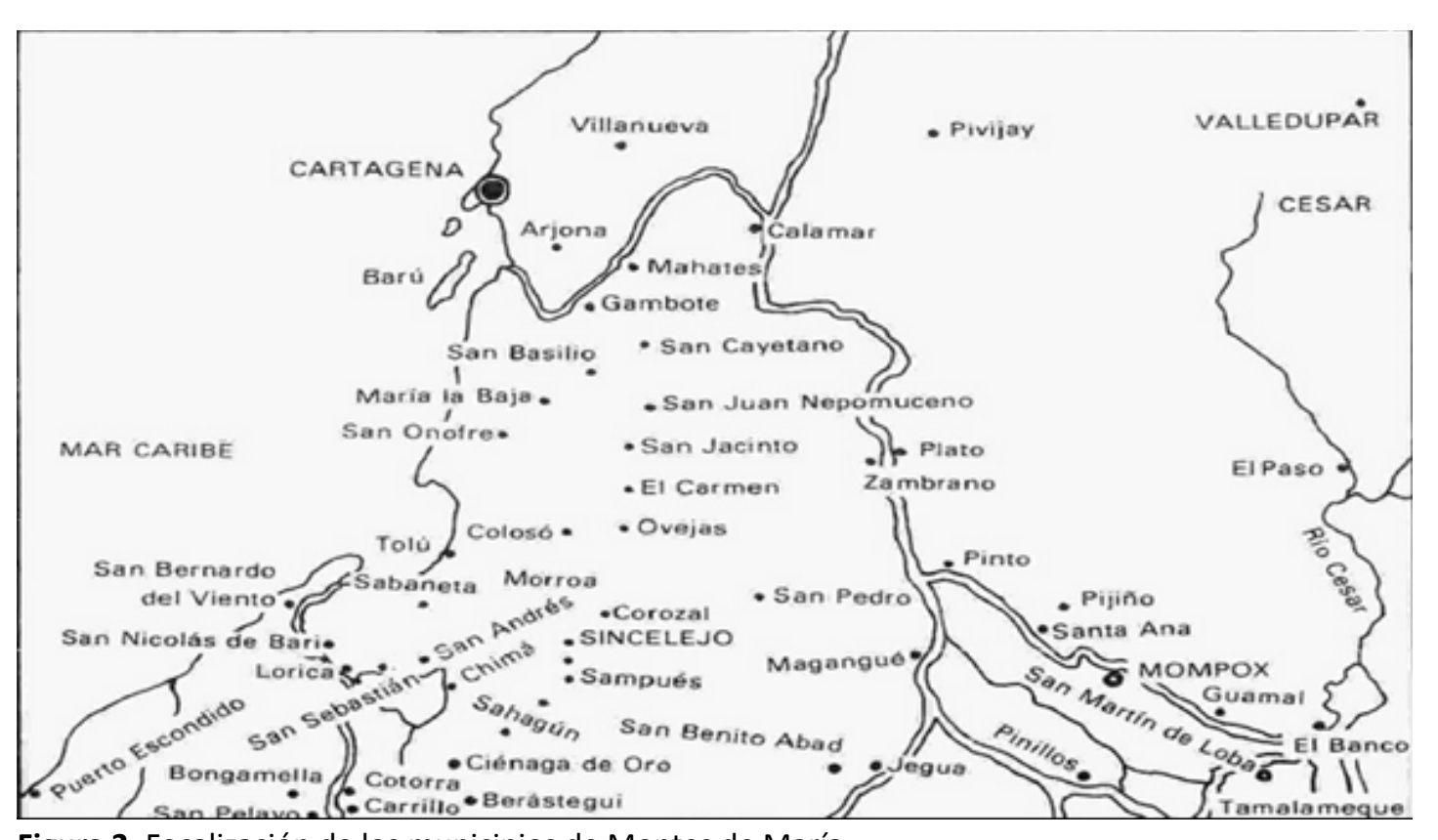

Figura 2. Focalización de los municipios de Montes de María

Fuente: Fals Borda, O. (2002). Historia doble de la Costa. 4. Retorno a la Tierra, segunda edición palmente. En Bolívar, se efectúan tomas de tierra en Carmen de Bolívar, San Jacinto, María la Baja (Fals Borda, 2002).

Los conflictos sociales más recientes (década de los 80), son una continuación de los conflictos de las décadas de los 60 y 70, pero que se han ido complejizando con la entrada de nuevos actores que han planteado en las regiones sus propias pretensiones frente a la debilidad del Estado. Este, desde la perspectiva local, se muestra ineficiente (en sus instituciones formales) dando cabida a un complejo entramado de instituciones informales.

La geografía de los Montes de María ha sido, desde los años 80, teatro de operaciones por el dominio territorial de la zona, con presencia armada y violenta de las guerrillas Fuerzas Armadas Revolucionarias de Colombia (FARC) y Ejército de Liberación Nacional (ELN), luego con los primeros grupos de Autodefensas (Clan Los Mendez, y después la entrada de las Autodefensas Unidas de Colombia, AUC), grupos de ultraderecha cuyo propósito en un principio era "limpiar" la zona de los militantes de izquierda; cada grupo con específicos intereses sobre el territo-

Información recopilada* en el marco de esta investigación, da cuenta de presencia de reductos del movimiento Partido Revolucionario de los Trabajadores-PRT, antes de 1980, en las inmediaciones de María la Baja reducto que posteriormente se retiró de la zona. También señalan la presencia de otros movimientos de izquierda desde los años 60 como el Partido Comunista Marxista-Leninista-PCML y el MIR (Movimiento de Izquierda Revolucionaria). Este último se convertiría posteriormente en la organización armada MIR PATRIA LIBRE, con una importante actividad en la región. En la década de los 90 se conformó una alianza entre el MIR y el Ejército de Liberación Nacional-ELN, la cual operó especialmente en los municipios de San Juan Nepomuceno, El Carmen y San Jacinto, bajo la denominación de Unión Camilista Ejército de Liberación Nacional-UCELN. A finales de los 90 finalizó tal alianza cuando una facción del ELN se dividió, dando origen al grupo Corriente de Renovación Socialista-CRS, con presencia en Ovejas. Este grupo se desmovilizó en 1993, en la vereda Flor del Monte de ese municipio (ILSA, 2012, p.13).

1985 a 1990 (final del periodo presidencial de Virgilio Barco)

En una escala micro, a finales de 1985, el escenario local muestra marcadas discrepancias entre las organizaciones campesinas y las instituciones del Gobierno departamental en torno de las políticas de manejo del sector agropecuario. Los líderes campesinos manifestaban su inconformidad con el tratamiento desobligante al que eran sometidos por parte del ente territorial, debido al incumplimiento de reuniones de trabajo sobre temas relativos a la actividad agropecuaria. Consideraban un irrespeto que fueran cita-

[ REVISTA VIS IURIS I No. 3, Vol. 2 | 127 - 158 I Enero-Junio, 2015 I Universidad Sergio Arboledal I Escuela de Derecho I Seccional Santa Marta, Sede Centro ]. 
campesino y no concurriera ninguna autoridad de orden departamental para la discusión de políticas agrarias. Este anuncio es hecho por la Coordinación de Organizaciones Campesinas integrada por las ANUC-María la Baja, ANUC-Sincerín, ANUC-Malagana, ANUC-Gamero, ANUC-Mahates y la Federación Sindical Agraria FENSA (El Universal, 1985, 6 de dic.), situación que posteriormente se agudiza con la convocatoria del líder Alirio Traslaviña* a una marcha campesina debido al incumplimiento de los programas de Servisalud y Caminos Vecinales, que partió desde Magangué y contó con más de 15 mil labriegos (El Universal, 1986, 24 de enero). Los campesinos habitantes no solo de Montes de María sino de Bolívar en general vivían en condiciones precarias, circunstancia que propició esta protesta social.

En un nivel más macro, analizando el contexto Caribe y el contexto nacional, se presentan diversos escenarios que afectan el ámbito social y político, trazando un escenario de agitación, fragmentación y debilidad del Estado. Así las cosas, por una parte mientras a nivel nacional se llevaban a cabo los diálogos de paz, por la otra, se libraban cruentos combates en algunos territorios (Urabá y en Siloé)**. Estos escenarios marcan la caótica

El3 de julio de 1985 en efecto Alirio Traslaviña movilizó a 6.000 campesinos y se tomó el Parque del Centenario en Cartagena, para plantear ante el entonces gobernador los delegados enviados por el presidente Belisario ancourt, las exigencias de los campesinos: vías, hosptales con médicos permanentes, escuelas, electricidad y

profesores.
El periódico local (diciembre 1 de 1985) daba cuenta de mientos entre el ejército y el M-19 en Siloé, con tanques situación nacional que contrasta para la fecha con los pocos sucesos de beligerancia nivel local. Estos hechos son corroborados por las afirmaciones de la Comisión de Paz:

"El año de prueba o espera pactado con las FARC vencerá cronológicamente este domingo, pero la fecha no se manejará con inflexibilidad, $y$ de hecho el acuerdo ha sido prorrogado para permitir la realización de los nuevos diálogos en procura dic.).

Este periodo revela un gran empoderamiento de las FARC, a partir del análisis de las manifestaciones a la prensa, efectuadas por el dirigente comunista Alberto Rojas Puyo, quien ratificaba el cese al fuego, aun cuando estaba próximo a vencerse el plazo de los diálogos que se venían adelantando "si la treintena de frentes de las FARC volvieran a la arena, el país se daría cuenta de la gravedad que significa una guerra generalizada" (El Universal, 1985, 1 de dic.).

La prensa local, específicamente el diario El Universal, registra para la época (1985) la sección referida a los municipios, un vida relativamente pacífica en los pueblos de Montes de María, en los que se dan cuenta de acontecimientos de la vida cotidiana como las fiestas patronales, corralejas, celebraciones de reinados y elección de rei-

y artillería pesada". Por otra parte también anunciaba Urabá, combates de las tropas de la Cuarta Brigada en Urabá antioqueño contra las FARC, caen 22 guerrilleros". nas populares e inauguración de escuelas. Quiere decir ello, que los conflictos sociales previos, si bien tenían que ver con necesidades insatisfechas de la población, aún no se sentía la presencia a gran escala de grupos alzados en armas.

En este sentido, este territorio era ajeno a conflicto que se libraba en otras latitudes; sin embargo, ya el Comandante de la Policía de Bolívar y el Ministro daban cuenta de una estrategia de expansión de las guerrillas. El titular del diario local del 6 de diciembre relataba:

"El comando de la Policía división Bolívar denuncia la llegada a Cartagena de dirigentes subversivos con la intención de incorporar a jóvenes a la lucha armada. Armando Ramírez, comandante de la Policía, informó que se han llevado a cabo allanamientos en algunos barrios que han arrojado como resultado la detención de personas y el decomiso de bombas y granadas, lo mismo que propaganda subversiva" (El Universal, 1985, 6 de diciembre).

Los allanamientos se practicaron en La Boquilla y El Pozón, barrios periféricos de Cartagena. Hechos ocurridos con posterioridad como la detonación el día 24 de enero de 1986 de un artefacto explosivo, camuflado en un paquete dejado abandonado en un bus de transporte urbano que fue activado por una mujer que resultó herida, confirmaban la información del Comandante de la Policía sobre la llegada de subversivos a la capital del departamento de Bolívar.
Paulatinamente vemos cómo las notas de prensa local van registrando aumento de la criminalidad en Bolívar, tal como los secuestros a ganaderos de la región, así:

“Uno de los más crueles ataques de la guerrilla fue realizado por cerca de un centenar de integrantes del ELN, que bombardeó en la madrugada del 16 de mayo, el puesto de Policía. El saldo fue de 5 uniformados muertos y 6 heridos" (El Universal, 1985, 17 de mayo).

Se muestra el incremento de la confrontación hacia el sur del departamento y la consolidación en esa zona del ELN. Esta situación posteriormente da cabida a finales de la década, a la entrada al departamento de los grupos de autodefensa para recuperar territorios de fuerte presencia de estas guerrillas. En este sentido, se muestra el aumento de la movilización de las guerrillas: "Más de cien insurgentes de la columna "José Solano Sepúlveda" del ELN se tomaron en la madrugada la población de San Martín de Loba, Bolívar, donde murieron tres miembros de la fuerza pública" (El Universal, 1986, 23 de nov.)

Las hostilidades y combates en el territorio impulsaron a los campesinos a efectuar protestas ante el Gobierno, frente al temor por sus vidas e integridad personal: "2.3000 labriegos entre mujeres y niños procedentes de Santa Rosa del Sur y Simití, llegaron a la cabecera municipal de San Pablo para exigir al Gobierno el cese de los enfrentamientos tre el Ejército y la guerrilla" (El Universal, 1987, 7 de oct.). 
Paralelamente a los enfrentamientos de la paramilitares en El Carmen de Bolívar; según guerrilla con el Ejército en territorio rural, hechos ocurridos el 24 de marzo de 1999, reen el casco urbano de Cartagena se desa- latados por una mujer víctima entrevistada, ta una oleada de actos terroristas. El 26 de procedente de la vereda de Tierra Grata: septiembre de 1989 el titular de la prensa resalta: "Cartagena sacudida por el terrorismo", cuando el sexto piso del Hotel Hilton fue destruido por la detonación de un artefacto explosivo y, posteriormente, el 25 de octubre y el 7 de noviembre del mismo año, dos atentados más acaecieron a saber: la explosión de 20 kilos de dinamita en un centro comercial de la ciudad y la explosión de un carro-bomba cargado con 25 kilos de dinamita en una avenida del sector turístico de Bocagrande.

Nuevamente, el 19 de marzo de 1990, se registra otro atentado con carro-bomba frente al Centro Comercial Bocagrande, que dejó un saldo de 38 personas heridas.

Vemos cómo hacia finales de la década de los 90 , hay un recrudecimiento de la guerra en Bolívar con la ofensiva del ELN, esta se expresa en el aumento de la criminalidad, el pago de vacunas, extorsión a los ganaderos y la realización de falsos retenes militares o también llamados "pescas milagrosas". Por ejemplo, el realizado cerca al municipio de María la Baja, en el que resultó secuestrado el dirigente deportivo y Secretario de Recreación y Deportes del departamento de Bolívar, Luis Alfredo Romano y el ciudadano argentino Edgardo Rigonni (La Nación, 1999, 8 de marzo)

Para esa fecha, ya hacían presencia grupos
"Yo soy de Tierra Grata, pero en esa época yo estudiaba en un colegio del Carmen, y me iba a pasar las vacaciones allá, cuando íbamos para allá nos encontramos con unas personas vestidas de militar que dijeron que eran paramilitares, eran 14, nos bajaron del carro y nos separaron a los hombres de las mujeres, el chofer se escapó y lo mataron, el carro lo quemaron, yo estuve seis horas retenida; con lista en mano buscaban a alguien y por radio nos obligaban a dar el nombre, nos decían que si nos movíamos nos mataban".

1991 a 2002 (final del periodo presidencia de Andrés Pastrana)

En esta década el actor violento que se consolida y marca una pauta de violencia en la región son las Autodefensas Unidas de Colombia, quienes hacían presencia en el Departamento desde 1997. Mientras tanto, e sur de Bolívar se había consolidado como zona de dominación del ELN, que demostraba fortaleza a través de los ataques, golpeaban la infraestructura institucional, apareciendo en columnas de 100 y 200 hombres, originando combates con la fuerza pública de manera creciente y generando una percepción de caos social e institucional. Por en el proceso de consolidación de las AUC a preguntaban por los que tenían retenidos, nivel nacional, Carlos Castaño, en compañía de otros jefes paramilitares, acordaron el in greso al sur de Bolívar, diseñando una estrategia desde el departamento de Santander, para entrar a disputar el control territorial a esta guerrilla.

Con estas metas, en 1997 Carlos Castaño Salvatore Mancuso, Ernesto Báez y Oscar Restrepo entre otros, establecen una alianza para ingresar a esa región. Llevar a cabo el objetivo planeado exigió establecer dominio desde Barrancabermeja para poder conquistar el sur de Bolívar. La estrategia se desarrolló sistemáticamente aunque tardó más de cuatro años en consolidarse. Según el Observatorio del Programa Presidencial para los Derechos Humanos y el DIH (2005, como se cita en Ortiz, 2010):

“[E]n 1998 se había logrado generar unos pequeños asentamientos de grupos de autodefensa en Santa Rosa y Salvatore Mancuso y alias Popeye lograron establecerse en el casco urbano de Simití, mientras el grupo de Botero, desde Magangue incursionó en Tiquisio, Achí, Pinillo y Altos del Rosario. A partir de 1999, se produce una seguidilla de asesinatos, masacre, desapariciones, desplazamientos y torturas, así como de enfrentamientos en las zonas rurales" (p.10)

Para 1991 las Fuerzas Armadas de Colombia intensificaron las operaciones hacia el sur de Bolívar, situación registrada por la prensa local así:
“Operación Rastrillo: Una intensa operación adelantaron las fuerzas combinadas de la Policía, el Ejército y la Armada, contra la columna guerrillera que atacó el 30 de abril de 1991 a las poblaciones de San Pablo y Cantagallo. Ese día, poco después de las 4 de la tarde, 120 guerrilleros llegaron por tierra y por rio" (El Universal, 1991, 8 de mayo).

Por otra parte, las guerrillas no solo tenían frentes de operación rural sino urbana, las cuales también tenían la capacidad de golpear la infraestructura de Cartagena; por ejemplo, con la carga explosiva que detonó en la pista del Aeropuerto Internacional Rafael Núñez el 12 de julio de 1990 y que fue atribuido a una célula urbana de las FARC. En medio de la inestabilidad del orden público en el Departamento, el 2 de enero de 1993 fue capturado en Cartagena Humberto Callejas Rúa, jefe militar del EPL.

El escenario a nivel local era cada vez más complejo a medida que avanzaba la década, las notas de prensa son significativas para ilustrar los golpes a la infraestructura institucional y el debilitamiento de los lazos sociales: "40 guerrilleros del frente 37 de las FARC destruyeron la Inspección y Subestación de Policía y asesinaron a un agente y a dos campesinos en San Cayetano, municipio de San Juan Nepomuceno" (El Universal, 1994, 14 de nov.).

"ELN se lleva a 21 concejales: La guerrilla secuestró a 9 concejales, al tesorero municipal y a un aspirante a la Alcaldía 
de Simití, sur de Bolívar. Los guerrilleros afectaba la movilidad en el Departamento y reunieron a la población en la plaza y les cuestionaba a la gobernabilidad y el dominio aseguraron que se trataba de un secuestro territorial de la fuerza pública, en la medida político, además revelaron el secuestro de que la gente por temor evitaba movilizarse; 12 concejales en el municipio de San Pa- transitar una vía constituía a la población ciblo" (El Universal, 1997, 17 de ago.).

vil en blanco de accionar de las guerrillas:

En 1998 se producen enfrentamientos armados entre guerrilla y paramilitares, originando desplazamientos masivos de población, que daban cuenta de que en el sur se estaba en guerra:

"Arde sur de Bolívar: Los paramilitares se tomaron el llamando "corredor de la muerte" del ELN en el sur de Bolívar, dejando a su paso 30 muertos, entre civiles, guerrilleros y miembros de las autoridades. En su arremetida, los paramilitares quemaron los corregimientos de Pueblito Mejía, jurisdicción de Barranco de Loba, y Carnisala de Arenal obligando a más de 1.5000 personas a desplazarse hacia otras regiones" (El Universal, 1998, 12 de nov.).

“Por más de siete horas, 30 uniformados adscritos al Comando de la Policía de San Martín de Loba repelieron el ataque de 200 guerrilleros que intentaron tomarse estación. Pese a la magnitud del ataque, solo dos agentes resultaron levemente heridos mientras que 10 guerrilleros fueron dados de baja" (El Universal, 1998, 2 de agosto).

Las prácticas de las "pescas milagrosas" eran cada vez más frecuentes, situación que

"La muerte implacable en Bolívar: doce personas que alegaban cumplir una misión bélica, montaron un retén en la vía de San Jacinto a Cerro Maco. Retuvieron por varias horas a más de 50 personas, seleccionaron a cuatro conductores, quemaro sus vehículos y los asesinaron" (El Universal, 1999, 15 de marzo).

Para el 2000, el escenario social y político en Bolívar estaba bastante caldeado por la discusión de establecer una zona de despeje en el sur del departamento para adelantar los Diálogos de Paz con el ELN, este hecho orignó muchas protestas campesinas e inclusiv bloqueos de la Troncal de la Paz.

Mientras que al sur los alcaldes se reunía con los senadores del departamento para dialogar sobre el despeje, hacia el norte de este, las FARC se tomaban el municipio de Córdoba (Bolívar) y para diciembre del 2000 fue secuestrado en Cartagena, el exministro de Desarrollo Fernando Araújo Perdomo.

En el mes de febrero del 2000, ocurrió la masacre de El Salado (corregimiento de Carmen de Bolívar, donde hubo 59 muertos) $y$ en el mes de marzo las masacres en San muertos. Mientras los paramilitares arremetieron contra la población civil por presuntos "ayudantes de las guerrillas", las guerrillas efectuaron incursiones en San Jacinto, y quemaron la Alcaldía de Turbaná (Bolívar). Este panorama propició enfrentamientos múltiples entre la fuerza pública y las guerrillas: en el mes de abril del 2000, en la jurisdicción de San Isidro, municipio de San Jacinto, hubo un enfrentamiento entre el Batallón 33 de la Infantería de Marina y el Frente 37 de las FARC.

También en el mes de abril los paramilitares dieron muerte a 10 personas en El Carmen de Bolívar (veredas Hato Nuevo y Motaperro), mientras que por otra parte en este mismo municipio, las FARC atacaron el puesto de peaje vial, y dos meses después (en junio), fueron asesinados Emiro Osorio Borré, aspirante a la Alcaldía de San Juan Nepomuceno Eliseo Manuel Bustos Castañeda, aspirante a la Alcaldía de Montecristo.

Para el mes de julio del 2000, la prensa da cuenta de los combates entre las guerrillas y os paramilitares en el sur de Bolívar dejando un saldo de 60 guerrilleros muertos por una parte y 17 paramilitares por la otra.

En octubre ocurrió la masacre de Macayepo en la que resultaron asesinadas 12 personas en inmediaciones del municipio de El Carmen de Bolívar y se registró un secuestro de 20 personas en la vía El Carmen-Ovejas.

\section{2 hasta la fecha}

A continuación se da cuenta de las masacres Este periodo ha sido caracterizado como el ocurridas en la zona:

\begin{tabular}{|c|c|}
\hline VEREDA O CORREGIMIENTO & MUNICIPIO \\
\hline Pichilín & Colosó \\
\hline San lsidro & El Carmen de Bolivar \\
\hline Caracolí & ElCarmen de Bolivar \\
\hline Capaca y Campoalegre & Zambrano \\
\hline Las Palmas & San Jacinto \\
\hline ElSalado & ElCarmen de Bolivar \\
\hline $\begin{array}{l}\text { Las Brisas, San Cayetano, } \\
\text { Mampuján }\end{array}$ & $\begin{array}{l}\text { Maríala Bajay } \\
\text { San Juan Napomuceno }\end{array}$ \\
\hline Motaperro & El Carmen de Bolivar \\
\hline La Libertad & San Onofre \\
\hline $\begin{array}{l}\text { Flor del Monte, } \\
\text { Canutal y Canutalito }\end{array}$ & Ovejas \\
\hline Chengue & Ovejas \\
\hline Retiro Nuevo & María la Baja \\
\hline Chinulitoy EICerro & Colosó \\
\hline Macayepo & ElCarmen de Bolivar \\
\hline La Aventura & Córdoba \\
\hline
\end{tabular}

La finalización de la década coincide, en el escenario político nacional, con el final del periodo presidencial de Andrés Pastrana Arango (1998-2002), la proximidad de los copor el fallido proceso de paz que tuvo como escenario la zona de distensión conformada por los municipios de La Uribe, Mesetas, La Macarena y Vista Hermosa en el departamento del Meta, y por San Vicente del Caguán en el departamento del Caquetá, zona que fue creada mediante Resolución 85 de 14 de octubre de 1998. más cruento en el conflicto armado en la en Montes de María, 1997-2004 
zona de Montes de María. Está marcado por la finalización del periodo presidencial de Andrés Pastrana y el inicio del primer periodo presidencial de Álvaro Uribe Vélez, quien asumió la presidencia de la mano de la política de Seguridad Democrática, con la cual se redefinió el papel de algunos actores armados, específicamente los actores contrainsurgentes en la dinámica de la guerra a nivel nacional, regional y local.

A nivel macro se evidenció, por una parte, la guerra en todo el territorio de la Nación y el fortalecimiento y rearme de las FARC mientras que de otra, se hizo visible el hastío del pueblo colombiano frente al discurso incoherente de la guerrilla. Estas condiciones configuraron el escenario que aseguró la victoria de Álvaro Uribe Vélez, candidato que ofreció un tratamiento diferente a los grupos al margen de la ley en contraposición al continuismo de las políticas del saliente presidente Pastrana.

A nivel internacional, varios medios registraron cómo Uribe Vélez consolidó su favoritismo:

"Álvaro Uribe Vélez es el candidato favorito a las presidenciales del 26 de mayo en Colombia, con un holgado 52 por ciento de las intenciones de voto. La prensa de su país sostiene que su éxito se debe a que siempre ha mantenido un mismo discurso de campaña: mano dura con las FARC. "Desde el inicio del proceso de paz que el presidente Andrés Pastrana comenzó con la guerrilla, Álvaro Uribe mantuvo su oposición a este y planteó una política de seguridad", dijo a Página/12 Edwin Gutiérrez, editor de política del noticiero de RCN, "mientras que los otros candidatos -Horacio Serpa (liberal) y Noemí Sanín (conservadora)- apoyaban la negociación".

A medida que fue agotándose el proceso de negociación, y luego al romperse toda posibilidad de diálogo entre el Gobierno la principal guerrilla colombiana el pasado 20 de enero, Uribe fue ganando terreno. Cuando Uribe decidió salir del tradiciona Partido Liberal y formar su propio movimiento Primero Colombia, no ofrecía amenaza a su antes compañero de partido, Horacio Serpa, quien hasta diciembre era el favorito (un 35 por ciento) mientras Uribe arrancaba tercero (con un 2 por ciento) detrás de Noemí Sanín. “Él decide hacer su disidencia porque todo estab preparado para que Horacio Serpa fuera el único candidato liberal y no había consulta interna", explicó a este diario Luis Castela editor de política del diario El Universal. Castelar dice que al principio "Uribe era un candidato con pocas opciones pero que fue ganando votos por la situación misma del conflicto armado del país, porque el discurso de Uribe se centra en la autoridad" (Página|12, 2002, abril 21).

Justamente la llegada de Álvaro Uribe Vélez a la Presidencia marca una nueva dinámica en el conflicto armado, teniendo en cuenta que bajo el lema de "seguridad democrática" se implementó en todo el territorio nacional una escalada militar contra las guerrillas, situación que recrudeció la guerra, y que a mediados de la década produjo, al amparo de la institucionalidad, la desmovilización de algunos bloques de las AUC

En septiembre de 2002, el Gobierno Nacional, respaldado por el Estado de Conmoción Interior que estuvo vigente hasta el 30 de abril de 2003, declaró 26 municipios de los departamentos de Bolívar y Sucre como Zona de Rehabilitación y Consolidación (ZRC), como medida para el control del orden público. De Bolívar se tomaron: Arroyo Hondo, Calamar, El Carmen de Bolívar, Córdoba, El Guamo, Mahates, María la Baja, San Jacinto, San Juan Nepomuceno y Zambrano; de Sucre los municipios de San Onofre, Colosó, Chalán, Ovejas, Tolú Viejo, Sincé, Galeras, El Roble, San Pedro, Corozal, Sincelejo, San Juan de Betulia, Los Palmitos, Morroa, Buenavista y San Benito Abad. No obstante, la desaparición de la ZRC, el Gobierno persistio en su objetivo de lograr el restablecimiento del orden público (Observatorio del Programa Presidencial de Derechos Humanos y DIH, 2005).

as políticas implementadas para la recuperación del territorio, en lo que respecta al departamento de Bolívar y la subregión de los Montes de María arrojaron resultados positivos, en la medida que se logró mediante la acción militar la restauración de la gobernabilidad y el control de las carreteras de la región.

En enero de 2002 detonaron en Cartagen dos artefactos explosivos en el edificio inteligente en el sector de Chambacú y ese mismo día la Policía capturó tres hombres que transportaban en una camioneta macetas con cargas explosivas en el barrio Manga, aspecto que revela actividad subversiva tanto rural como urbana.

El 24 de enero del mismo año, la Infantería de Marina frustra un atentado guerrillero en el municipio de San Jacinto (Bolívar), tras 15 minutos de combate contra un reducto de la FARC, la situación en Bolívar era tan compleja que no hubo elecciones en 55 corregimientos, por las amenazas de los actores insurgentes, de hecho, las mesas de votación fueron trasladadas a las cabeceras municipales. Ya la violencia era generalizada en todo el departamento, en el sur el ERP llegaba a las viviendas lista en mano y seleccionaban a sus víctimas. Por otra parte comienzan a hacerse evidentes las conversaciones entre las AUC y militantes políticos de partidos tradicionales y entre las primeras y grupos de narcotraficantes.

En el 2003 continúan los secuestros en la subregión, es así como el ELN secuestró a 5 personas en una pesca milagrosa o retén ilegal en el sitio llamado Bajo del Oso, en el tramo de la Troncal de Occidente que comunica El Carmen con San Jacinto (EI Universal, 2003, 7 de febrero).

En el marco de la Política de Seguridad Democrática, Mahates, San Jacinto y San Juan recibieron los tres primeros pelotones de 
gión por ser Zona de Rehabilitación decretada por el Gobierno (El Universal, 2003, 6 de marzo).

En el 2005, aproximadamente 600 hombres pertenecientes al bloque Héroes de los Montes de María se desmovilizaron de las AUC, bloque que se le endilgan las masacres de Macayepo, Las Palmas, El Salado, San Onofre, entre otras localidades de los Montes de María (El Universal, 2005, 14 de julio).

La Política de Consolidación de la Seguridad Democrática (2006-2010) se propuso como transición para avanzar en la consolidación del control hacia la recuperación social del territorio, aunque implicó el aumento de la militarización en el departamento y de manera particular, en la subregión de los Montes de María.

En el marco de este aumento de operaciones de las FAC sucede el escape del exministro Fernando Araújo, luego de pasar seis años de cautiverio en manos de las FARC. El exministro caminó por los Montes de María durante cinco días antes de llegar a San Agustín lugar en donde se encontró con miembros de la fuerza pública (El Universal, 2007, 6 de enero)

En febrero de 2008, se realizó una manifestación sin precedentes contra las FARC, tanto en la mayoría de ciudades y municipios de país así como en diversos lugares del planeta, concentraciones y marchas bajo el lema "No más guerra, no más secuestro, no más FARC". Según registra El Universal, la Avenida Venezuela en Cartagena quedó chica para albergar a miles de manifestantes que mar- charon contra las FARC (2008, 5 de febrero).

Si bien las guerrillas siguen con su accionar a nivel nacional durante este año (2008), en los Montes de María su acciones son mínimas. Según el Informe de Alertas Tempranas de la Defensoría del Pueblo-SAT, en los departamentos de la región Caribe (Córdoba Sucre, Bolívar, Atlántico, Magdalena, La Guajira y Cesar) hacen presencia los grupos ilegales Los Urabeños, Águilas Negras, Los Paisas y Los Rastrojos (SAT, 2012).

Granada, Restrepo y Tobón (2009) señalan que desde el 2006, las autoridades del pais comenzaron a identificar acciones delictivas de grupos conformados o bien por reductos de los grupos paramilitares que no quisieron entrar en proceso de desmovilización o por grupos de desmovilizados que volvieron a rearmarse. En el departamento de Bolívar, la criminalidad comienza, a partir del 2008 a ser determinada por la actividad delictiva de estas nuevas bandas criminales, denominadas BACRIM. Según la Defensoría de Pueblo, "Estamos ante un nuevo fenómeno delincuencial en el que hemos podido identificar que estos grupos armados ilegales operan bajo nuevas denominaciones y nuevos jefes. También se observa el rearme de reductos que no participaron de la desmovilización como, por ejemplo, Los Rastrojos" (SAT, 2012)

Según el informe de monitoreo del SAT (2012), sobre los nuevos grupos armados posdesmovilización, estos buscan mantener, través de sus acciones de violencia, el control de los negocios del narcotráfico, la exac- ción de rentas, la extorsión, el préstamo por usura o paga-diario, el lavado de activos y el control social.

La persistencia del conflicto armado en Colombia, hoy muestra nuevos matices. Por una parte, evidencia el conflicto político tradicional mediado por una soterrada economí ilegal de extracción de recursos naturales y permeada por el narcotráfico por una parte y por la otra, el reacomodamiento social de grupos que aprendieron el arte de la guerra $y$ que mutan en una sociedad fragmentada aumentando los niveles de criminalidad en un contexto más urbano y más de delincuencia ordinaria al amparo, ya no del Derecho Internacional de los Derechos Humanos y del Derecho Internacional Humanitario, sino de las normativas del Derecho Penal naciona.

\section{Obstáculos para la superación del con-} flicto

Muy a pesar de que en los Montes de María se han ejecutado inversiones en el marco de proyectos sociales liderados desde el Departamento de la Prosperidad Social-DPS, cooperación internacional y la empresa privada, el reto para la superación de la situación de rezago y de conflicto enfrenta las misma razones históricas que tienen que ver con la violencia estructural, agravadas por la fragmentación social e institucional secuela de conflicto, estos obstáculos son:

\subsection{Política agraria y existencia a gran es} cala de cultivos agroindustriales

Los pobladores de la subregión de los Mon- tes de María han quedado expuestos en el territorio no solo por los embates de la guerra, coetáneamente han sido afectados por los cambios en las políticas públicas sectoriales, que han pasado de tener un talante proteccionista a uno neoliberal.

Si bien los expertos en desarrollo rural consideran que la implementación de políticas para el campo no se acompasa con un concepto de desarrollo fraguado desde las comunidades campesinas, por lo menos existía regulación desde el Gobierno Central que llevadas a cabo por el Ministerio de Agricultura $y$ otros entes con autonomía administrativa y financiera, se concretaban en proyectos que brindaban un tratamiento especial para el campo. Este tipo de orientación desde la política nacional ya no es tan claro, lo cual puede, en parte, ser explicado a partir de las redistribuciones de funciones y creación de nuevas instancias y responsabilidades con respecto al campo. Según Vargas, citado por Chalarcá (2009):

En el nivel nacional, se dio la creación del Viceministerio de Desarrollo Rural Campesino adscrito al Ministerio de Agricultura y del Consejo Nacional de Desarrollo Rural y Reforma Agraria, a estas instancias les correspondió la definición de las políticas, además de control y seguimiento de las mismas. A las entidades públicas descentralizadas, entre ellas el Fondo de Cofinanciación para la Inversión RuralDRI, el Plan Nacional de Rehabilitación, el INCORA, la Caja Agraria, FINAGRO, el ICA, el INAT, el Fondo de Organización y Capaci- 
tación Campesina y el Fondo EMPRENDER el sector. Sin embargo, puede comprobarse del IDEMA, les correspondió adelantar los la tendencia sostenida a priorizar el objetivo

programas y proyectos que les señalara la de la modernización, desarrollo e integración política (Vargas, 1994).

La internacionalización de la economía y la adopción de políticas económicas neoliberales con mínima intervención del Estado en la regulación, contribuyeron a afectar un sector económico que no podía entrar en el juego de actores internacionales debido a las fuertes asimetrías que han caracterizado diversas zonas de Colombia, asimetrías que se acentúan sobremanera en la competencia en el contexto internacional. Como se planteó anteriormente, el sector agropecuario sufría el flagelo de la violencia generada por el conflicto armado por una parte y por la otra el empobrecimiento y endeudamiento paulatino, la pérdida de tierras de los pocos que las tenían, y la riqueza de un reducido círculo, privilegiando una economía que beneficiaba la acumulación de tierras para actividades de ganadería extensiva y variación de la vocación tradicional de la tierra.

En los últimos 40 años, las políticas para el sector agropecuario y rural han respondido básicamente a la necesidad de lograr dos propósitos: 1) la modernización, desarrollo e inserción económica del sector y 2) el desarrollo social rural. Estos propósitos han sido incluidos en varios tipos de iniciativas y estrategias institucionales, traducidas en políticas sectoriales y plasmadas en instrumentos jurídicos o expresiones normativas que dan las pautas para la acción y delimitan las intervenciones de los agentes que actúan en económica del sector, por encima de los objetivos de desarrollo social rural, a los cuales se les ha otorgado un carácter complementario, orientado -esencialmente- a remover las limitaciones existentes para el pleno cumplimiento del propósito prioritario. Antes que políticas de desarrollo social rural, lo corto plazo para evitar conflictos sectoriales o para seguir garantizando unos estándares en los precios de los alimentos (Promontes, 2003, p.23)

Quiere decir ello que el desmonte de políticas proteccionistas afectó al campesino mediano y pequeño propietario, que frente a las pérdidas y poca rentabilidad del sector agropecuario, terminó acrecentando el fenómeno de migración del campo a la ciudad. En ese sentido, como lo plantea Promontes (2003).

"Los objetivos de desarrollo social rura surgen como paliativo ante los desequilibrios generados por las políticas de modernización agropecuaria, que beneficiaron tan solo a un reducido grupo $d$ productores y profundizaron condiciones de pobreza y rezago entre la mayoría de los habitantes rurales, así como el aumento de las tensiones sociales, la migración campo-ciudad, los incremen-

Una preocupación creciente de los habitanque se ha visto es una serie de proyectos de tos del desempleo, etc." (p.24). tes de los Montes de María es la existencia de monocultivos industriales, los cuales han ido sustituyendo los cultivos tradicionales en la zona como por ejemplo maíz, yuca, ñame, ajonjolí, tabaco, aguacate y diferentes tipos de frutas, reemplazándolos por cultivos como la teca, la palma aceitera, y otros destinados a la obtención de biocombustibles, quiere decir ello que este obstáculo está directamente relacionado con el modelo de desarrollo que se ha implementado en a zona, el cual confronta conceptualmente un modelo fundado en la explotación a gran escala para satisfacer al mercado y el modelo fundado en la economía campesina.

Información consolidada de fuentes primarias y secundarias evidencia que han venido legando a la región empresarios palmicultores de otras zonas del país, y que han incidido en la compraventa de tierras, asegurán dose el englobe de grandes extensiones, que posteriormente son utilizadas para el establecimiento de megaproyectos de monocultivos de explotación industrial, lo que pone en riesgo a la población de la región porque:

a. Amenaza la seguridad alimentaria de la región y el autosustento del campesino.

b. Empobrece al campesino porque los suelos sufren deterioro progresivo que los hace difíciles de recuperar.

c. Enriquece al comprador que es único, frente a muchos vendedores, creando en términos de justicia social, un monopolio que asegura el manejo de precios, trasladando la pérdida o contingencias de mercado al campesino y no a los propietarios de las empresas procesadoras de aceite.
Varias preguntas surgen ante esta situación: ¿el campesino elegiría con conocimiento informado, el destino de su tierra frente al deterioro progresivo ocasionado por la explotación a escala industrial?; si el Gobierno opta por un modelo de desarrollo agroindustrial diferente en la zona, al largo plazo, ¿cuál sería el impacto económico y social para la supervivencia de la familia campesina, el impacto ambiental sostenible y el impacto de las ciudades que históricamente se han abastecido de los productos alimenticios proporcionados por la agricultura convencional?; ¿a qué tipo de economía se le apuesta: a la economía de mercado, a una economía de tipo extractivo y del empresario que invierte en plantas industriales, en desmedro de la población nativa o el campesino que debe cuidar de su autosustento y de su hábitat natural? Un reto para el Gobierno es la conciliación de estas posiciones en aras de lograr un desarrollo social equitativo para la zona.

La agenda sobre construcción de paz que lidere el Gobierno Nacional deberá verse abocada a confrontar los costos políticos, económicos y sociales que, en aras de la consecución de una paz sostenible, deben privilegiar cierto tipo de desarrollo agropecuario. En ese sentido estamos de acuerdo con el planteamiento sostenido por Absalón Machado (2004):

"Esta discusión política no es de poca monta: optar por una u otra vía, es decir, optar por la protección o desprotección del agro, pasa hoy por la política antes que por la economía. Y es así porque en 
este debate se define nada menos que el El estudio en cuestión define como cadefuturo de un sector estratégico para el de- na productiva[e]l conjunto de actividades sarrollo, antes que los privilegios de unos que se articulan técnica y económicamente grupos de la sociedad, que en opinión de desde la producción y la elaboración de un los protagonistas del debate, se han con- producto agropecuario hasta su comercialivertido en buscadores de rentas y no en zación final. La cadena puede ser nacional promotores del desarrollo. La decisión de regional o local e involucra a productores, proteger al sector agropecuario y por tan- empresarios, gremios y organizaciones más to garantizar una seguridad alimentaria, representativos de un renglón específico de unos ingresos para los productores a costa la economía (Corporación para el Desarrollo de los consumidores y un empleo para los Participativo y Sostenible de los Pequeños habitantes rurales es una decisión que tie- Productores, 2009, p.13).

ne un costo económico alto para el país, frente a un costo político bajo" (p.24).

\subsection{Los problemas en torno a la tenencia de} la tierra

Una posibilidad viable para los campesinos que se encuentra documentada es la de estimular las cadenas productivas naturales en la zona, de hecho, existen empresas privadas como el grupo Nutresa (Compañía Naciona de Chocolates) que ya lo viene haciendo con la cadena productiva del ajonjolí, desde e marco de la responsabilidad social empresarial.

Este tipo de iniciativas se identificaron para la zona de Montes de María en un estudio llevado a cado por la Corporación para e Desarrollo Participativo y Sostenible de los Pequeños Productores, PBA, en la que participaron 67 organizaciones de pequeños productores rurales, en el marco del Laboratorio de Paz III, estudio que priorizó siete cadena productivas analizando la oferta y demanda local, regional y nacional y los perfiles de mercado por cada cadena productiva de ñame, yuca, plátano, miel de abejas, peces de cultivo, ajonjolí, y productos autóctonos.
Uno de los puntos álgidos de cualquier política pública de construcción de paz, cuyo objetivo sea la superación de los obstáculos para lograr una paz sostenible, tiene que ver precisamente con la tenencia de la tierra, tema que en Colombia es recurrente, $y$ de hecho origen primigenio de los conflictos sociales. Este aparte abarca dos aspectos relativos a tierra, el acceso o democratización de la propiedad de la tierra y su restitución en caso de despojo violento.

\section{El acceso a la propiedad de la tierra}

La economía campesina tiene su fundamento en el acceso a la propiedad de la tierra así lo plantea la Constitución de Colombi (2012) en su artículo 64, el acceso progresivo de los trabajadores agrarios a la propiedad de la tierra:

"Es deber del Estado promover el acceso progresivo a la propiedad de la tierra de los trabajadores agrarios, en forma individual o asociativa, $y$ a los servicios de educación, salud, vivienda, seguridad social, recreación, crédito, comunicaciones, comercialización de los productos, asistencia técnica y empresarial, con el fin de mejorar el ingreso y calidad de vida de los campesinos".

I acceso a la propiedad de la tierra tien que ver con un tema de justicia social; como se ha planteado desde la ANUC, "la tierra es de quien la trabaja". Precisamente, la propiedad de la tierra a favor del campesino ha sido frenada por los intereses de los latifundistas, por razones que van de la mano con el mismo sistema de clases y de castas locales frente a la vulnerabilidad manifiesta del campesino. Problema que se ha ido agravando con el tiempo, tomando tintes de contrarreforma agraria, de militancias de ultraderecha respaldadas por las elites locales y por el narcotráfico.

En perspectiva histórica, el acompañamiento del Estado en el acceso a la propiedad de la tierra ha sido nulo, en la medida que una política no puede ser apreciada en el marco de n programa cortoplacista; de hecho, siempre se ha dejado solo al campesino que de una u otra forma, o bien no puede acceder a su propiedad, debido a los múltiples requisitos establecidos, o, los que ya tenían la pequeña propiedad campesina la han perdido una vez que sobre esta se constituyeron garantías jurídicas que amparaban créditos que es fueron desembolsados precisamente en el marco de dichas políticas agropecuarias.
Por ello, este es uno de los aspectos más problemáticos a considerar en la construcción de una política pública de paz, en la medida que la costa Caribe, al igual que en el resto del país ha predominado la acumulación latifundista de tierras, aunque su tenencia haya cambiado de los propietarios tradicionales a testaferros de actores violentos.

Los inadecuados parámetros de redistribución de la tierra han posibilitado al campesino ser poseedor o propietario de minifundios, predios que fueron abandonados, despojados o vendidos a precios irrisorios, pero más allá de eso, ¿qué solución existe campesino que históricamente ha trabajado la tierra aportando su fuerza de trabajo, pero que no ha tenido acceso a su propiedad?

La Constitución de 1991 refleja el problema histórico de los campesinos en Colombia pero la Norma de qué sirve más allá de su eficacia simbólica si no va acompañada de la voluntad política que efectivice el acceso a la propiedad de la tierra anunciado.

\section{La restitución de tierras en la zona}

Según información suministrada por la Mesa de Víctimas de El Carmen de Bolívar, en lo que va corrido del 2013 han recibido 35 amenazas del autodenominado "ejército antirrestitución", a raíz del apalancamiento que desde la Mesa se están proporcionando a los procesos de restitución de tierras ante la Unidad a cargo del tema (Unidad de Restitución de Tierras). Estas amenazas han buscado crear un estado de terror para que los acto- 
res sociales desistan de sus reivindicaciones. De hecho, muchos líderes de la región han tenido que salir de sus municipios y ubicarse en ciudades como Cartagena y Barranquilla.

El conflicto armado en la zona propició e despojo y el abandono forzado de tierras, y ha sido muy complicado la recopilación de información predial que dé cuenta de la propiedad de dichos predios, por la imposibilidad de concluir el programa piloto de Manpuján, pionero en ejercicios de cartografía social, frenado ante la ausencia de información predial en el Instituto Geográfico Agustín Codazzi (IGAC). El conflicto armado, sumado a la corrupción administrativa, constituyó un círculo perverso para el despojo que hoy arroja como triste evidencia la judicialización de la Registradora de Instrumentos Públicos de El Carmen de Bolívar.

Los campesinos que vienen de procesos sociales de victimización por actos que infringen el Derecho Internacional de los Derechos Humanos y el Derecho Internaciona Humanitario, sufren un ciclo de revictimización inclusive frente a las prerrogativas establecidas por la Ley 1448 de 2011 desde las cuales se dictan parámetros de "reparación integral". Dichos parámetros consolidarían los procesos de reparación de tierras, previas las ritualidades de un proceso judicial mediante el fallo respectivo. Sin embargo, por las condiciones de inseguridad y de terror sembradas por los panfletos enviados por el ejército antirrestitución de tierras, se encuentran ante la disyuntiva de retornar a

sus tierras o de no hacerlo para salvaguardar su vida y la de su núcleo familiar.
No obstante lo anterior, una fortaleza posible para abordar esta temática es la institucionalidad presente en la región. En la zona está bien implementada la infraestructura administrativa encargada de la restitución. Por un lado está funcionando la Unidad de Restitución de Tierras, con sede en Cartagena, y en El Carmen de Bolívar, la cual opera a través de un grupo interdisciplinar que aglutina profesionales del Derecho, profesionales sociales e ingenieros catastrales. Este equipo recepciona las solicitudes y procede a estudiar los aspectos concernientes a la inclusió del predio en el Registro Nacional de Tierras Despojadas. En el marco de los principios de progresividad y gradualidad las intervenciones para la restitución se van iniciando dependiendo de las áreas territoriales focalizadas en el territorio.

A la fecha, en la zona funcionan dos juzgados especializados de restitución de tierras en el casco urbano de El Carmen de Bolívar y s hizo apertura de dos nuevos juzgados en la ciudad de Cartagena; en el Tribunal Superio de Distrito Judicial de Cartagena se nombraron tres magistrados de Restitución de Tierras.

Los juzgados especializados de El Carme de Bolívar han proferido tres sentencias de conformidad con los datos registrados por la Unidad Especializada en Restitución de Tierras. Estas sentencias han recaído sobre tierras despojadas en Mampuján (María la Baja).

Hasta el momento la parte procedimental de los procesos de restitución se están llevando a cabo con normalidad, pero los problemas de seguridad en la zona podrían resquebrajar la restitución de tierras, frente a las amenazas recibidas por los líderes, con lo cual se repetiría un nuevo ciclo de despojo y revictimizaciones, posteriores a los fallos judiciales respectivos.

\subsection{La débil institucionalidad democrática}

Las organizaciones de víctimas de los Montes de María no le tienen mayor fe a los procesos democráticos en sus regiones, ni a sus gobiernos locales, porque estos basan su modus operandi en atender solamente a su red de clientes. Si bien son notorios algunos empoderamientos de organizaciones de víctimas, estos lo han logrado como organizaciones de la sociedad civil en asocio con la cooperación internacional y apoyos de Gobierno central, en esta medida, las víctimas cuestionan a los gobiernos municipales.

La percepción generalizada de las víctimas* es que no son tenidas en cuenta para la toma de decisiones que les concierne, creen que la ey brilla por su eficacia simbólica en la medida que están creadas las plataformas de participación a nivel departamental y local sin embargo, son excluidas.

Los espacios de participación que existen de

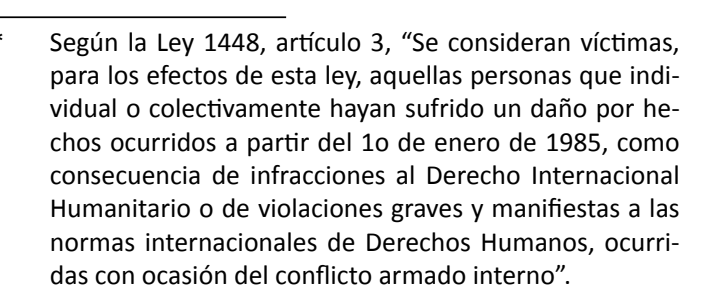

Según la Ley 1448, artículo 3 , "Se consideran victimas,
para los efectos de esta ley, aquellas personas que indi-
vidual o colectivamente hayan sufrido un daño por hechos ocurridos a partir del 10 de enero de 1985, como Humanitario o de violaciones graves y manifiestas a las das con ocasión del conflicto armado interno". conformidad con la Ley 1448 , como las OPD y los Comités de Justicia Transicional, son raramente convocados, debido a la falta de compromiso de los alcaldes y sus equipos en la realización de los Planes Integrales Únicos (PIU) y de los respectivos planes de acción para la atención a víctimas. También es evidente y preocupante el poco avance en las directrices dadas por la Corte Constitucional, especialmente los programas para mujeres contemplados en el auto 092, con lo cual este aspecto pone en entredicho los parámetros de una "reparación integral".

\section{Recomendaciones para la construcción}

de una política pública de paz y desarrollo regional

3.1. Formulación de una propuesta desde las organizaciones campesinas. OPD-Montes de María

La construcción de políticas de paz debe ser edificada sobre las asimetrías que determinan diferentes matices regionales, sobre todo en una región como los Montes de María. En este orden de ideas, si bien las políticas de paz deben ser tenidas en cuenta desde una dimensión individual, cobran relevancia las recomendaciones construidas desde los colectivos $u$ organizaciones de base campesina, teniendo en cuenta que desde estos espacios se articulan y lideran procesos a partir de las necesidades que giran alrededor de la comomía campesina y el empoderamiento de nuevos liderazgos desde lo local.

Los Montes de María han tenido una tradición de organización campesina a partir de 
las ANUC, sin embargo, el proceso de configuración de espacios de organizaciones con la característica de ser víctimas del conflicto armado, o campesinos en condición de desplazamiento, es más bien reciente.

Para los campesinos asociados en la OPD de Montes de María, se pueden identificar tres momentos en torno a su proceso organizativo: un primer momento fundacional, uno segundo de fortalecimiento y crecimiento, $y$ un tercer momento de incidencia.

Formalmente, como espacio de articulación, inicia sus actividades en el 2008 con la participación de 17 organizaciones a saber: Aso Mundo Nuevo, Aso Cucal, Aso Cascajalito, Aso Santafe, No hay como Dios, Asoprini, Aso Playón, Aso Pueblo Nuevo, Aso Cayeco, Aso Palo Altico, Aso Trinidad, Cabildo Indígena de la Pista, Mampuján, Aso Montes, San José de la Pradera, Aso Sena, Aso Cristo. Con posterioridad se unieron otras organizaciones. El segundo momento está marcado po el aprendizaje y consenso con otras organizaciones y vinculación de otras nuevas, como Asocare, JAC Los Ángeles y Asoprasan.

“Durante el año 2010, las organizaciones integrantes del espacio, participamos de un proceso de formación en derechos y ciudadanía con énfasis en el derecho al erritorio, que además permitieron la interrelación con otras organizaciones de la zona, con sentires, potencialidades $y$ necesidades comunes, estableciéndos relaciones de confianza entre ellas. De esta manera, se crean condiciones para la participación de otras organizaciones de los Montes de María, y entonces cuando organizaciones del Carmen de Bolivar, San Jacinto y Ovejas, entran a aportar al proceso" (OPD Montes de María, 2012).

Desde el colectivo de OPD Montes de María, se realizó el siguiente análisis DOFA, características presentes en el contexto, las cuales servirán de referente para el análisis y planteamiento posterior de elementos que han de ser tenidos en cuenta como matices regionales necesarios y diferenciadores, a saber:

\section{DEBBLLDADES

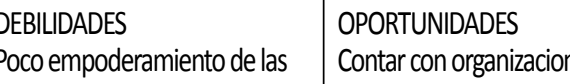 Falta de autonomía como organización. Poca disposición para la participación en espacios de formación y de incidencia fuera de la región por parte algunos participantes. Poca estabilidad económica de los participantes FORTALEZAS local, regional y nacional. Líderes comprometidos con el desarrolloy defensa del territorio. Líderes capacitados en Derechos Humanos. Buena capacidad de incidir. Seruna organizacion solidaria. Figura 4. DOFA OPD Montes de María
Fuente: Documento de OPD-Montes de Maria (2012)}

En el contexto de las organizaciones montemarianas, cuya economía ha sido tradicionalmente campesina, resultan extraños, y si se quiere amenazantes, los modelos impulsados en nombre del desarrollo, sin la realización previa de estudios concienzudos sobre el impacto social, económico, político y ambiental de la zona. Por ello la exploración de las debilidades y amenazas manifestadas por las organizaciones, cuentan prospectivamente para direccionar las recomendaciones aportadas desde las bases campesinas. Los lineamentos que constituirían las recomendaciones, desde la OPD Montes de María, serían los siguientes:

El diseño y desarrollo de un modelo de desarrollo económico (economía campesina) que tenga en cuenta el desarrollo rural sostenible y la seguridad alimentaria.

Programas que promuevan pedagógicamente el cuidado de recursos naturale tanto para los campesinos como para los foráneos.

- Políticas de regulación y control de monocultivos a gran escala (ejemplo: Palma aceitera).

- La seguridad de la región para el ejercicio libre de derechos de ciudadanía.

- Apoyo institucional a los procesos de restitución de tierras.

Fortalecimiento de apoyos técnicos para los procedimientos para elaborar plan de desarrollo sostenible necesario para la Zona de Reserva Campesina.

Apoyo al campesino para el acceso a la propiedad de la tierra y la productividad económica (apoyo con semillas, asesoría técnica y otros).

Programas de saneamiento básico en la vivienda rural y acceso a educación para jóvenes y adultos (cumplimiento universal de DESC).

Inclusión de los enfoque diferenciales de acuerdo con la Ley para campesinos, negritudes e indígenas.
3.2. Zona de reserva campesina en Montes de María

Las zonas de reserva campesina fueron creadas en Colombia a través de la Ley 160 de 1994, por medio de la cual se crea el "Sistema Nacional de Reforma Agraria y Desarrollo Rural Campesino, se establece un subsidio para la adquisición de tierras, se reforma el Instituto Colombiano de la Reforma Agraria y se dictan otras disposiciones", el Decreto 1777 de 1996, el Acuerdo 024 de 1996 y acuerdos proferidos por la Junta Directiva del INCORA, con lo cual nuevamente se ratifica lo que se ha venido sosteniendo en esta monografía, que históricamente hemos implementado normativas referidas al problema agrario, pero han sido completamente ineficaces.

En este sentido, la acumulación de la tierra en manos de latifundistas contrasta con las normas legales que determinan o conno$\tan$ que la tierra debe tener un fin social o de explotación económica que contradice la tenencia de tierras para engorde. El artículo 31 de la ya mencionada Ley 160 de 1994, establece:

"Son motivos de interés social y de utilidad pública para la adquisición y expropiación de bienes rurales de propiedad privada, o los que formen parte del patrimonio de entidades de derecho público, los definidos en los ordinales segundo, tercero $y$ quinto del artículo 10. de la presente Ley. En consecuencia, el Instituto Colombiano de la Reforma Agraria podrá, adquirir mediante negociación directa de tierras o mejoras, o decretar su expropiación, con 
el objeto de dar cumplimiento a los fines de interés social y utilidad pública definidos en esta Ley, en los siguientes casos:

Para las comunidades indigenas que no las posean, cuando la superficie donde estuvieren establecidas fuere insuficiente, o para sanear las áreas de resguardo que estuvieren ocupadas por personas que no pertenezcan a la respectiva parcialidad.

2. En beneficio de las personas o entidades respecto de las cuales el Gobierno Nacional haya establecido programas especiales para tal fin.

3. Con el objeto de reubicar a los propietarios u ocupantes de zonas que deban someterse a un manejo especial o que sean de interés ecológico. El INCORA adelantará los respectivos programas de adquisición de tierras y mejoras en coordinación con el Ministerio del Medio Ambiente o la corporación autónoma regional correspondiente, dando preferencia a los ocupantes de tierras que se hallen sometidas al régimen de reserva forestal, de manejo especial o interés ecológico, o las situadas en las áreas que conforman el Sistema de Parques Nacionales Naturales.

4. Dotar de tierras a los habitantes de regiones afectadas por calamidades públicas naturales sobrevinientes, sin afectar las reservas de recursos forestales.

5. Para dotar de tierras a los hombres y mujeres del campo de escasos recursos, minifundistas, a las mujeres campesinas jefes de hogar $y$ las que se hallen en estado de desprotección conómica y social por causa de violencia, el abandono o la viudez. cuando no hubiere acuerdo de negociación entre los campesinos y los propietarios, o en las reuniones d concertación, en los casos que determine la Junta Directiva (subrayas fue ra de texto).

Al efectuar un análisis más profundo de la ley en cuestión, se puede apreciar que cobran vigencia los postulados del Estado Social de Derecho preconizados por la Constitución de 1991, sin embargo, el tema no es de la mayor o menor justicia o validez de las normas, que de hecho la tienen, sino de aspectos que van más allá, que tienen su explicación en otros factores que involucran, entre otros:

Falta de voluntad del Estado en la implementación de las políticas públicas. Captura del Estado a manos de élites nacionales y locales.

Vulnerabilidad del trabajador agrario que se encuentra huérfano ante las to tuosas rutas de acceso a dichos programas y proyectos.

Nótese cómo el numeral 5 del artículo 31 que se viene comentando, de manera clar define los "motivos de utilidad pública" que darían pie a negociaciones directas de tierras con los latifundistas o en su defecto la expropiación para volver útiles las tierras de engorde, adquiridas conforme a la ley, que posibilitarían en el marco de las instituciones una revolución agraria que de una vez permita un equilibrio de la balanza de la justicia social a favor de la dotación de tierras "para hombres y mujeres de campo de escasos recursos". Este último aspecto recoge a todos os trabajadores agrarios, bien desde afectados por la violencia como personas, hombre y mujeres sujetos de especial protección constitucional, como por ejemplo las protegidas por ser minorías étnicas y por razones de enfoques diferenciales.

La investigación de campo efectuada da cuenta de la creciente preocupación de la OPD frente a los trámites administrativos relacionados con la creación de las Zonas de Reserva Campesina en Montes de María cuando desde el 30 de julio de 2009* se iniciaron los trámites respectivos. Al respecto, los líderes han desarrollado un proceso de articulación de actores en torno del proceso y han estado efectuando visitas técnicas a otras zonas del país, para nutrirse de los aprendizajes de otros líderes agrarios. Expresan la preocupación coyuntural a la tensión que suscita la frágil economía campesina frente a la acumulación de tierras propia del modelo de desarrollo industrial.

En Colombia hay seis zonas de reserva campesina constituidas (ver ubicación en el mapa) y varias en proceso de constitución de hecho según información suministrada por la página web del INCODER, e información de las OPD-Montes de María, se inició el trámite administrativo para la constitución

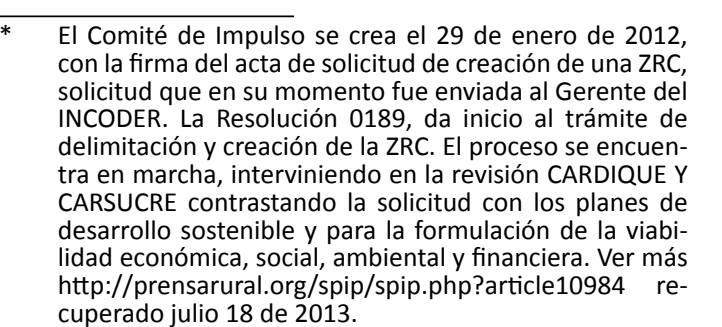

de la zona como tal, estipulando dentro de sus planes la realización de los estudios técnicos que posibiliten la implementación de la

\section{ZRC constituidas:}

1. Cabrera (Cundinamarca), 44.000 has.

2. Bajo Cuembí y Comandante (Puerto Asís, Putumayo), 22.000 has.

3. Sur de Bolívar, municipios de Morales y Arenal, 29.110 has.

4. Guaviare, municipios de Calamar, El Retorno y San José del Guaviare, 463.600 has.

5. Cuenca del Río Pato y Valle de Balsillas (Caquetá), 88.401 has.

6. Valle del río Cimitarra (Antioquia y Bolívar), 184.000 has.

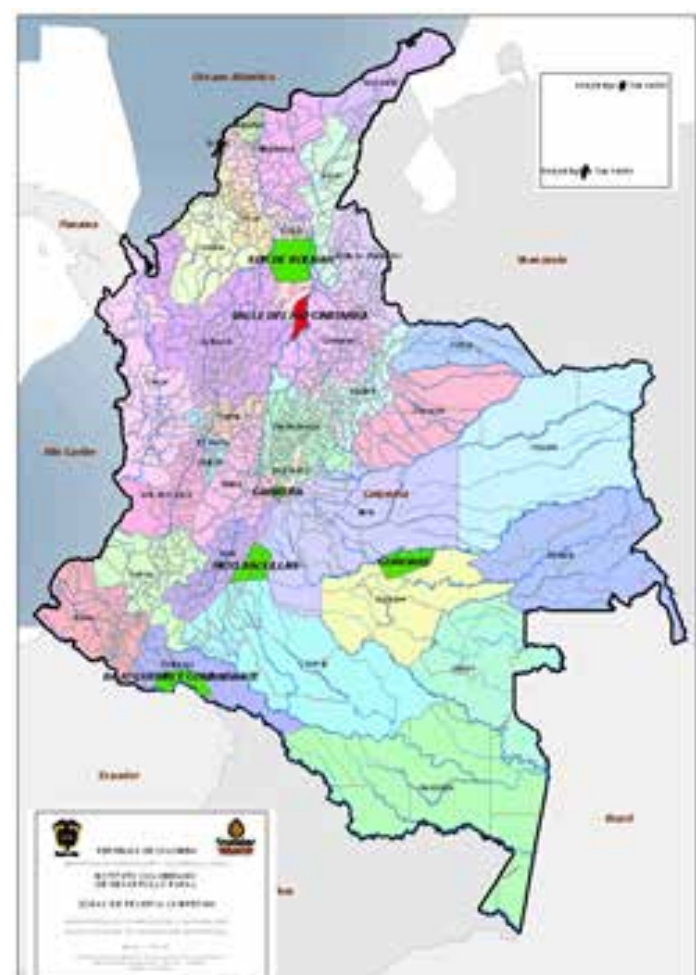

Higura 5. Zonas de Reserva Campesina constituidas en Colombia
Fuente: INCODER (2013) 
Tomando como referente el contexto de nes de objetivos para la política pública de violencia que se ha vivido en la zona y la desarrollo regional, paz y estabilidad en la debilidad institucional tanto nacional como subregión.

territorial, debe ser fortalecido de manera prioritaria el proceso de establecimiento de la ZRC, no solo en la región de Montes de María, sino en todo el territorio nacional. Esto evitaría o por lo menos amortiguaría los efectos de la descampesinización del campo tributaría sostenibilidad ambiental y fomentaría la economía campesina en condiciones de justicia social.

Objetivos de la Política de Construcción de

A partir de la identificación de conflictos sociales y de su caracterización para la región de Montes de María, retomando los diagnósticos presentados en los documentos de referencia para la zona, es posible presenta los siguientes elementos a considerar como ejercicio de construcción de recomendacio-

\begin{tabular}{|c|c|c|}
\hline CATEGORÍA & OBJETIVO DE POLÍTICA & SERVICIOS INSTTTUCIONALES \\
\hline Existencia & $\begin{array}{l}\text { Todos/as vivos } \\
\text { Todos/as saludables } \\
\text { Todos/as con educación } \\
\text { Recreación }\end{array}$ & $\begin{array}{l}\text { 1. Mecanismo de prevención en salud (sistema de Saludu) Hospitales re- } \\
\text { gionales y locales } \\
\text { Sisben } \\
\text { 2. Sistema de educacaión, cobertura en educación, meta de cobertura } \\
\text { en educación rural, No. de escuelas rurales, No. programas locales de } \\
\text { enseñanza desesscolarizaday campesina, adulto mayor. } \\
\text { No. cuposs ENNA, Cupos Ceres, formación agropecuaria } \\
\text { Secretaría de Deportes y Cultura (No. de canchas y parques-cobertura) }\end{array}$ \\
\hline Ciudadanía & $\begin{array}{l}\text { 1-Todas y todos participan en espacios institu- } \\
\text { cionales } \\
\text { 2-Todas y todos participan en espacios sociales }\end{array}$ & $\begin{array}{l}\text { No. Comités de Participación en Comités de Justicia Transicional, y es } \\
\text { pacios de OPD } \\
\text { Participación en Juntas de Acción Comunal, Juntas de Padres de Familia, } \\
\text { JAL, Comités Comunitarios } \\
\text { Participación en espacios de comunicación y radiales }\end{array}$ \\
\hline
\end{tabular}

\begin{tabular}{|c|c|c|}
\hline $\begin{array}{l}\text { Seguridad } \\
\text { yConvivencia }\end{array}$ & $\begin{array}{l}\text { Todos protegidos } \\
\text { Ninguno/na sometido a extorsión ni a crimina- } \\
\text { lidad }\end{array}$ & $\begin{array}{l}\text { Evaluación servicios de } \\
\text { Fuerzas milttares, } \\
\text { No. Estaciones de Policía-CAl } \\
\text { No. Patrullajes } \\
\text { No. de Juecesy fiscales, atención URI } \\
\text { Lineas de atención nurgencia } \\
\text { Programas de Derechos Humanosy Convivencia } \\
\text { Esquemas de Seguridad Ĺderes } \\
\text { Brigadas de Consultorios Jurídicosy y mecanismos de acceso a lajusticia- } \\
\text { programas de conciliación }\end{array}$ \\
\hline $\begin{array}{l}\text { Desarrollo } \\
\text { regional }\end{array}$ & $\begin{array}{l}\text { Todos con trabajo } \\
\text { Todos con vivienda rural } \\
\text { Zonas de Reserva Campesina }\end{array}$ & $\begin{array}{l}\text { Cobertura del subsidios de Ministerio de Agricultura yarticulaciones con } \\
\text { UMATA } \\
\text { Asistencia técnica } \\
\text { Cobertura de Servicios de INCODER } \\
\text { Programa integral de restitución de tierras } \\
\text { Operacionalización y marcha de estudios técnicos para el establecimien- } \\
\text { to de ZRC }\end{array}$ \\
\hline
\end{tabular}

\section{CONCLUSIONES}

Aunque la consecución de un acuerdo de paz parece cercana, a la luz de los hechos y de las fuerzas e intereses descritos en este documento, lo más factible es que lograr una paz positiva, sostenible y duradera en el año 2013, sea todavía un escenario remoto.

Los matices que arroja la investigación efectuada, consultada desde las voces mismas de los actores sociales, corroboran los resultados de serios estudios académicos relativos a la existencia de agudas asimetrías que conducen a la violencia estructural, principal obstáculo para la construcción de una paz positiva.

El escenario de los Montes de María es complejo por cuanto la familia campesina aún no recupera su capacidad de agencia, para avanzar hacia la autosostenibilidad. Por lo tanto, aunque se aprecian liderazgos de hombres y mujeres fortalecidos en los marcos de los proyectos ejecutados en la zona, difícilmente podrían ser sostenibles si no se mejoran las condiciones de vida, la seguridad y el funcionamiento de las instituciones.

No es posible hablar de una sociedad del postconflicto, cuando existen en Montes de María zonas que se encuentran ubicadas por debajo de la línea de pobreza, es decir, en la miseria. El análisis de las condiciones de indicadores de desarrollo social y la de indicadores de desarrollo económico de la zona, especialmente de los municipios María la Baja y El Carmen de Bolívar, lo evidencian.

Con respecto a los indicadores de desarrolo social, salvo las familias que viven en los cascos municipales cumplen mínimamente la cobertura de los DESC, porque en general, las familias de estos municipios están lejos de tener la cobertura básica de los mismos derechos.

En cuanto a los indicadores de desarrollo económico, existen serias tensiones entre los modelos de desarrollo que han venido siendo apalancados desde el Ministerio de Agricultura en la zona, que confrontan el modelo 
de economía campesina, frente al modelo de Arias, A. (2010). Análisis del conflicto armaexplotación agroindustrial del campo, razón do. MOE y Corporación Nuevo Arco Iris, Mopor la cual se propone como alternativa el nografía Político Electoral departamento de impulso de la Zona de Reserva Campesina, Bolívar 1997 a 2007 En: http://moe.org.co/ esquema que protegería al campesino de los home/doc/moe_mre/CD/PDF/bolivar.pdf apetitos de acumulación de tierra marcada por el mercado.

\section{CIDER documento maestro.}

Finalmente, es importante señalar la debili- Congreso de la República de Colombia. Ley dad en la articulación de la institucionalidad local, los Comités de Impulso Locales y Comités Facilitadores y líderes en general. En este orden de ideas, los actores locales no se sienten satisfechos con la gestión de las Alcaldías de los municipios que parecen no haber trascendido el clientelismo y la corrup-

ción, que presentan serías deficiencias en la elaboración y trazado de planes de desarroIlo, de tal suerte que tienen más impacto las articulaciones que se efectúan desde las Gobernaciones y desde proyectos apalancados por el Gobierno Central, que las iniciativas, si las hay, propuestas por las autoridades locales.

\section{REFERENCIAS}

Aaron, E. (2012, diciembre). Los objetivos de desarrollo del milenio en Bolívar: Avances y retos hacia el 2015. Economía \& Región, 6(2), 153-216.

AECID - ILSA (2012). Montes de María. Entre la consolidación del territorio y el acaparamiento de tierras. Aproximación a la situación de Derechos Humanos y del Derecho Internacional Humanitario 2006-2012. Colombia: Agencia Española de Cooperación Internacional para el Desarrollo.
160 de 1994. "Por medio de la cual se crea el sistema nacional de reforma agraria y desarrollo rural campesino, se establece un subsidio para la adquisición de tierras, se reforma el Instituto Colombiano de la Reforma Agraria y se dictan otras disposiciones".

Congreso de la República de Colombia. Ley 1448 de 2011. "Ley de Víctimas y restitución de tierras".

Constitución de Colombia (2012). Colombia: Editorial Leyer.

Corporación para el Desarrollo Participativo y Sostenible de los Pequeños ProductoresPBA (2009). Caracterización de las cadenas productivas priorizadas en la región Montes de María. Colombia: Unión Europea, RDPM-

Chalarcá, Y. (2009). Qué tan rural es el desarollo: el desarrollo rural desde una óptica institucional. Revista Colombiana de Ciencias Pecuarias.

Espinosa, A. ( 2012). "Los objetivos de desarrollo del milenio en Bolívar: avances y retos $6(2)$. hacia el 2015". Revista Economía \& Región
Fals, O. (2002). Historia doble de la Costa 4. El retorno a la Tierra. Segunda edición. Universidad Nacional de Colombia. Colombia: El Ancora Ediciones.

Galtung, J. (1969). Violencia paz e investigación para la paz "en la paz". México: Fontamara.

Grupo de Memoria Histórica (2010). La tierra en disputa. Memorias del despojo y resisencias campesinas en la Costa Caribe 19602010. Informe del Grupo de Memoria Histórica de la Comisión Nacional de Reparación y Reconciliación.

Granada, S., Restrepo, J. \& Tobón, A. (2009). Guerra y violencias en Colombia: herramientas e interpretaciones. Pontificia Universidad Javeriana.

Instituto Internacional de Estudios del Caribe-Universidad de Cartagena. Sistema de Información Territorial de los Montes de María. http://www.sitmma.org/index.php/ noticias

Instituto Latinoamericano para una Sociedad y el Desarrollo Alternativo-ILSA (2012). Zonas de Reserva Campesina. Elementos Introductorios y de debate. Bogotá: Gente Nueva Editorial.

Instituto Geográfico Agustín Codazzi-DNP \& Gobernación Sucre y Bolívar (2010). Caracterización del desarrollo territorial en la Región de Montes de María. Colombia: DPN. (2004). La academia y el sector rural. Uni- PRE. Colombia. ción Territorios. de Cartagena. nizativo. versidad Nacional de Colombia. Centro de

Observatorio del Programa Presidencial para los Derechos Humanos y el DIH (2005). Panorama actual de Bolívar.

Presidencia de la República de Colombia (2009). Informe al Congreso. Departamento Administrativo de la Presidencia de la República-DAPRE. Recuperado en: http://wsp. presidencia.gov.co/dapre/Documents/Informe-Congreso/Informe_congreso_2009.pdf

Programa de las Naciones Unidas para el Desarrollo (2003). Programa de Desarrollo Paz de los Montes de María-PROMONTES.

Observatorio de Cultura Política, Paz, Convivencia y Desarrollo en los Montes de María (s.f.). El Laboratorio de Paz en los Montes de María. Una aproximación a su contexto. Con位

Organizaciones de Población Desplazada de Montes de María (2012). Documento Orga-

Observatorio del Caribe Colombiano-OCARIBE-Departamento Nacional de Planeación. (2011). Visión prospectiva de los Montes de María 2032. Lineamientos estratégicos de la subregión. Colombia: OCARIBE.

Presidencia de la República de Colombia REVISTA VIS IURIS I No.3, VVo. 2 I 127 - 158 I Enero-Junio, 2015 I Universidad Sergio Arboledal I Escuela de Derecho I Seccional Santa Marta, Sede Centro 
Presidencia de la República de Colombia (2005). Panorama actual de Bolívar. Observatorio del Programa Presidencial para los Derechos Humanos y el Derecho Internacional Humanitario. Colombia.

Programa de las Naciones Unidas para el Desarrollo-PNUD (2010). "Los Montes de María: análisis de conflictividad". Informe entregado por el área de paz, desarrollo y reconciliación del PNUD.

Periódico El Universal de Cartagena. 6 de diciembre de 1985.

Periódico El Universal de Cartagena. 17 de mayo de 1985.

Periódico El Universal de Cartagena. 24 de enero de 1986.

Periódico El Universal de Cartagena. 23 de noviembre de 1986.

Periódico El Universal de Cartagena. 7 de octubre de 1987.

Periódico El Universal de Cartagena. 8 de mayo de 1991.

Periódico El Universal de Cartagena. 14 de noviembre de 1994.

Periódico El Universal de Cartagena. 17 de agosto de 1997.

Periódico El Universal de Cartagena. 15 de noviembre de 1998.

Periódico El Universal de Cartagena. 2 de agosto de 1998.
Periódico El Universal de Cartagena. 15 de marzo de 1999.

Periódico El Universal de Cartagena. 7 de febrero de 2003.

Periódico El Universal de Cartagena. 6 de marzo de 2003.

Periódico El Universal de Cartagena. 16 de julio de 2005.

Periódico El Universal de Cartagena. 6 de enero de 2007.

Periódico El Universal de Cartagena. 5 de febrero de 2008.

Rawls, J. (1995). Teoría de la justicia. Fondo de Cultura Económica.

\section{CONSULTAS WEB}

http://restituciondetierras.gov. $\mathrm{co} /$ ?action $=$ article \&id $=207$

http://prensarural.org/spip/spip. php?article10984

Diario La Nación. Marzo 8 de 1999. En: http://www.lanacion.com.ar/130466-colombia-secuestran-a-un-argentino. Recuperado $11 / 06 / 2013$.

Diario Página|12, Argentina. Abril 21 de 2002. http://www.pagina12.com.ar/diario/ elmundo/subnotas/4-2168-2002-04-21.html 25 de junio de 2013.

Sistema de Alertas Tempranas-SAT | 2012-01-13. Ver más en http://www. defensoria.org.co/red/?_item $=0301 \&$ _ secc $=03 \& \mathrm{ts}=2 \& n=1421$ 